\title{
Rhodium-Catalyzed Synthesis of Sulfur Ylides via in Situ Generated lodonium Ylides
}

\author{
Janakiram Vaitla, ${ }^{*}+,+$ Kathrin H. Hopmann, ${ }^{\dagger, *}$ and Annette Bayer ${ }^{*}$ \\ ${ }^{\dagger}$ Hylleraas Centre for Quantum Molecular Sciences, The Arctic University of Norway, N-9037 Tromsø, Norway \\ ${ }^{\star}$ Department of Chemistry, The Arctic University of Norway, N-9037 Troms $\varnothing$, Norway \\ Supporting Information Placeholder
}

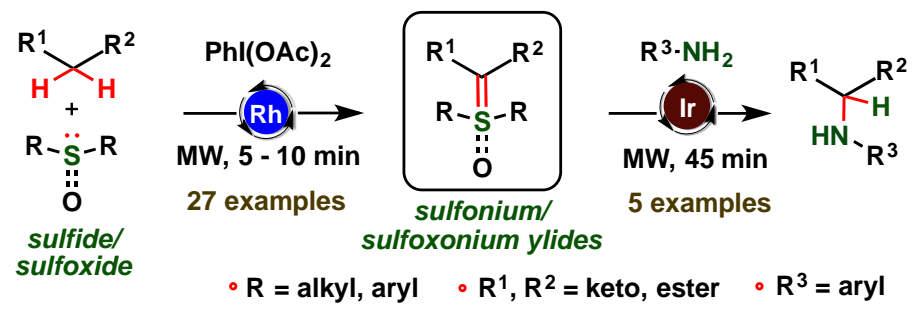

ABSTRACT: A convenient strategy for the synthesis of sulfur ylides via rhodium-catalyzed coupling of in situ generated iodoni-
um ylides with sulfides or sulfoxides has been developed. A wide range of sulfur ylides were obtained in moderate to good yields
from inexpensive sulfur compounds and active methylene compounds at short reaction time (MW, $5-10$ min) or $12-16 \mathrm{~h}$ at rt.
Furthermore, these sulfoxonium ylides were used as novel acceptor/acceptor carbenes for N-H insertion reactions.

Sulfur ylides are important synthetic precursors in organic transformations. ${ }^{1}$ Initially, sulfur ylides were used mostly for epoxidation, cyclopropanation, aziridination reactions, Stevens rearrangement, and [2,3]-sigmatropic shift reactions. ${ }^{2}$ Asymmetric versions of all these reactions were also described. Recently, these reagents have found application in the synthesis of complex molecules through cascade cyclizations. ${ }^{3}$ Their synthetic potential was well demonstrated in the synthesis of numerous bioactive natural products and pharmaceuticals. ${ }^{4}$ Besides synthetic exploration, sulfur ylides also exhibit antimicrobial properties. ${ }^{5}$ Similar to diazo metal carbenes, sulfur ylides produce metal carbenes when subjected to metals under suitable conditions. ${ }^{6}$ Most of the sulfur ylides are crystalline, bench-stable compounds, do not produce gas, and are not explosive. These characteristics make sulfur ylides promising substitutes for diazo compounds, particularly in large-scale reactions. ${ }^{7}$ Recently, we have observed that sulfoxonium ylide derived iridium carbenoids can undergo selective $\mathrm{N}-\mathrm{H}$ and C$\mathrm{H}$ insertion reactions. ${ }^{8}$

Generally, sulfur ylides can be prepared i) from sulfonium and sulfoxonium salts followed by deprotonation with strong ba$\operatorname{ses}^{3 c, 9}$ or ii) by the reaction of sulfides or sulfoxides with metal carbenes generated from $\alpha$-diazo carbonyl compounds. ${ }^{10}$ These methods have drawbacks related to the prior synthesis and handling of diazo reagents and the use of strong bases or stoichiometric amounts of metal salts for decomposition of the diazo compounds. Thus, it would be desirable to develop efficient and operationally simple protocols for the direct preparation of sulfonium/sulfoxonium ylides. In this context, Maulide and co-workers synthesized sulfonium ylides using bis[ $\alpha, \alpha$-bis(trifluoromethyl) benzyloxy]diphenylsulfur (Martin's sulfurane) as a doubly activated ylide transfer reagent under mild reaction conditions with good to excellent yields (Scheme 1). ${ }^{11}$ Although this process allows a direct synthesis of sulfonium ylides, it requires a relatively costly ylide transfer reagent $(88 € / \mathrm{g})^{12}$ and is limited to diphenyl groups on sulfur. To the best of our knowledge, there are no reports on direct access of sulfoxonium ylides.

Scheme 1. Approaches to Sulfonium and Sulfoxonium Ylides 


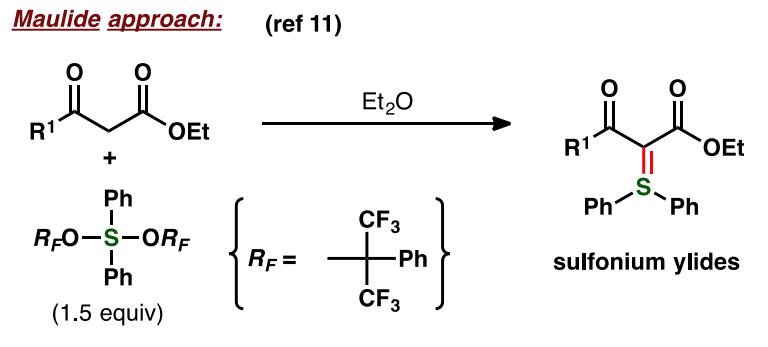

This Work:

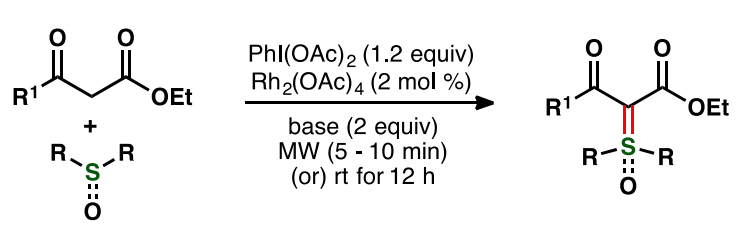

sulfonium/ sulfoxonium ylides

Inspired by a recent report on the use of in situ generated iodonium ylides as substitute for diazocarbenes in a Buchner reaction, ${ }^{13}$ we became interested in exploring a related approach in the direct preparation of sulfur ylides. We envisioned that in situ generated iodonium ylides obtained from phenyliodonium diacetate $\left(\mathrm{PhI}(\mathrm{OAc})_{2}\right)$ and active methylene compounds may react with commercially available sulfoxides or sulfides to provide sulfur ylides.

\section{Scheme 2. Metal Catalyzed Selective Reactions of in situ} Generated Iodonium Ylide ${ }^{a}$

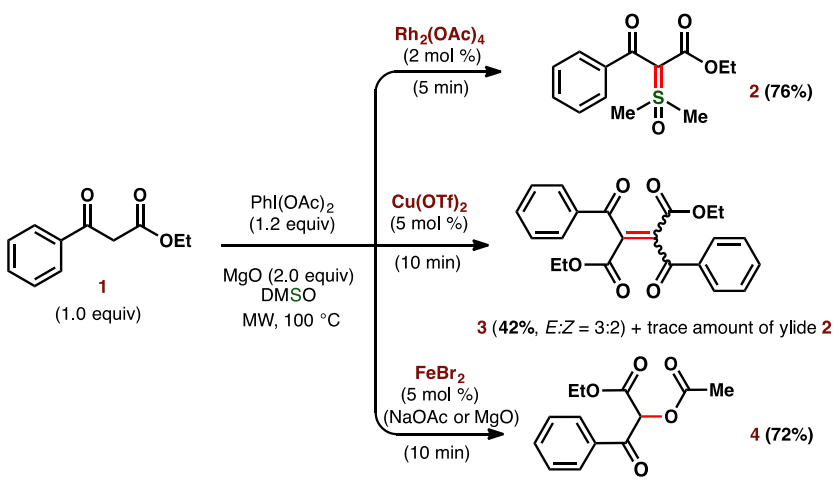

${ }^{a}$ Conditions: 1 (1.0 mmol), $\mathrm{PhI}(\mathrm{OAc})_{2}(1.2 \mathrm{mmol})$, catalyst (2-5 $\mathrm{mol} \%), \mathrm{MgO}(2.0 \mathrm{mmol}), \mathrm{DMSO}(2 \mathrm{~mL}), \mathrm{MW}\left(100{ }^{\circ} \mathrm{C}\right), 5-10$ $\min$.

We initiated our investigations by screening various catalysts $(\mathrm{Cu}, \mathrm{Rh}, \mathrm{Fe}, \mathrm{Ni}$, and $\mathrm{Ir}$ ) and reaction conditions (see the Supporting Information) for the $\mathrm{PhI}(\mathrm{OAc})_{2}$-mediated coupling of dimethyl sulfoxide (DMSO) and active methylene compound 1. The best results were obtained with $\mathrm{Rh}(\mathrm{OAc})_{2}(2 \mathrm{~mol} \%)$ and $\mathrm{MgO}$ (2.0 equiv) providing the desired sulfoxonium ylide 2 in $76 \%$ yield (Scheme 2). The reaction was surprisingly fast (5 min) with microwave-assisted heating, perhaps due to the high solubility of iodonium ylides in DMSO and large excess of the sulfoxide reagent. Using $\mathrm{Cu}(\mathrm{OTf})_{2}$ instead of $\mathrm{Rh}(\mathrm{OAc})_{2}$ in similar conditions afforded dimerized product 3 in $42 \%$ yield $^{14}$ and a trace amount of ylide 2 . Interestingly, using $\mathrm{FeBr}_{2}(5 \mathrm{~mol} \%)$ and $\mathrm{MgO}$ or $\mathrm{NaOAc}$ (2 equiv) as base afford- ed acetate inserted compound $\mathbf{4}$ in $72 \%$ yield as exclusive product.

With the optimized rhodium-catalyzed conditions for synthesis of sulfoxonium ylides $\mathbf{2}$ in hand, we then investigated the substrate scope of this method (Scheme 3). A range of $\beta$-keto esters and 1,3-diketones and malonates were efficiently transformed to their corresponding sulfoxonium ylides $\mathbf{2 a - u}$ in moderate to good yields (40-80\%). Aryl-substituted $\beta$-keto esters containing electron-donating or electron-withdrawing and halo substituents on the benzene ring $(\mathbf{1 a}-\mathbf{g})$ gave slightly better yields when compared to alkyl substituted $\beta$-keto esters $(\mathbf{1 h}-\mathbf{l})$. The size of the alkyl substituent on $\beta$-keto esters $(\mathbf{1 h}-\mathbf{l})$ did not affect the yields of the reaction. $\beta$-Keto esters with heteroaromatic substituents, such as furan and indole groups, did also afford the corresponding sulfoxonium ylides $\mathbf{( 2 \mathbf { m }}$, 2n), albeit in moderate yields (46-48\%). The reactions of cyclic and acyclic 1,3-diketones bearing aromatic or aliphatic groups gave the corresponding ylides $(\mathbf{2 o}-\mathbf{2 r})$ in good yields (77-81\%), whereas malonate esters $(\mathbf{2 s}, \mathbf{2 t})$ reacted less efficiently and with moderate yields (40-46\%). The reaction afforded only trace amounts of the desired sulfoxonium ylides when one of the acceptor groups was a sulfone, nitro or cyano group and simple ketones did not provide the desired sulfoxonium ylides. Gratifyingly, the reaction of ethyl benzoylacetate with diphenyl sulfoxide in 1,2-dichloroethane as solvent afforded corresponding sulfoxonium ylide $\mathbf{2 u}$ in reasonable yield $(58 \%)$.

Scheme 3. Scope and Limitations of Sulfoxonium Ylide Formation $^{a}$ 

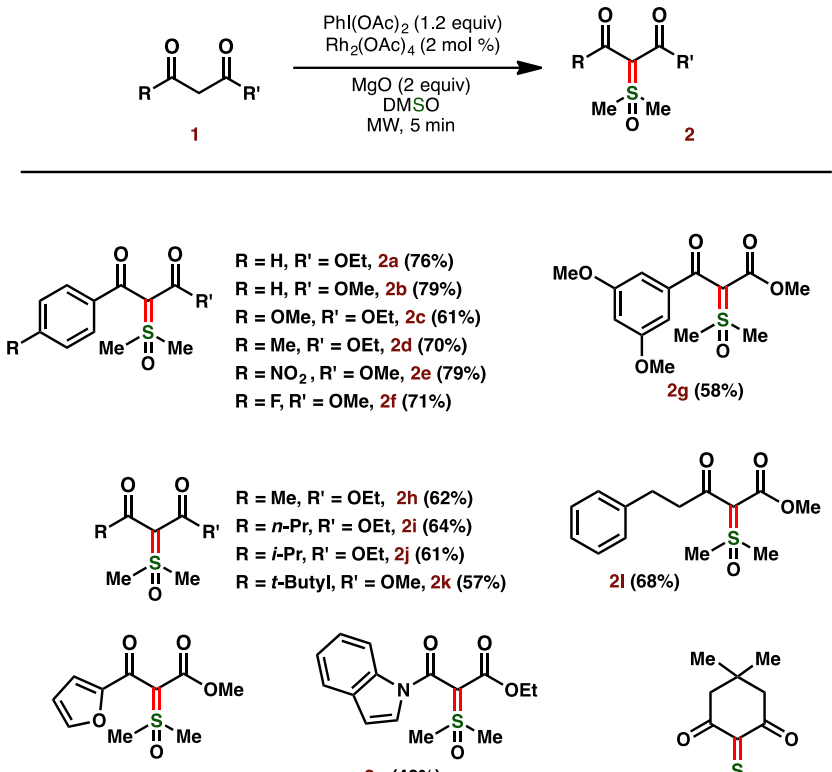

$2 \mathrm{~m}(48 \%)$

2n $(46 \%)$
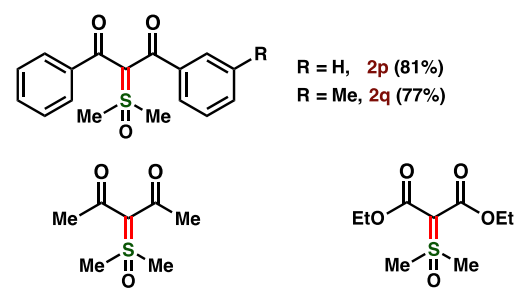

2s (40\%)

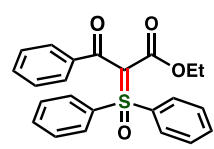

$2 \mathrm{u}(58 \%)^{b}$

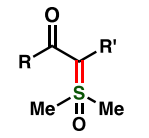

$\mathbf{R}=\mathrm{Ph}$,

$\mathrm{R}^{\prime}=\mathrm{SO}_{2} \mathrm{Ph}, \mathrm{NO}_{2}, \mathrm{CN}$

(trace)
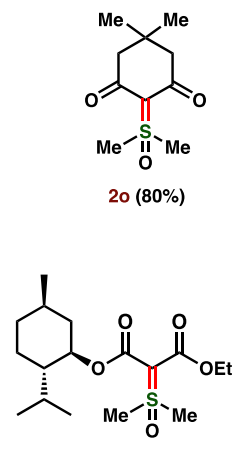

$2 t(46 \%)$

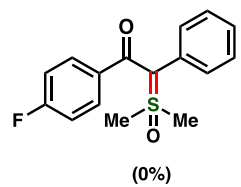

$\%$

${ }^{a}$ Reaction conditions: 1 ( $\left.1 \mathrm{mmol}\right), \mathrm{PhI}(\mathrm{OAc})_{2}(1.2 \mathrm{mmol})$, $\mathrm{Rh}_{2}(\mathrm{OAc})_{4}(2 \mathrm{~mol} \%), \mathrm{MgO}(2 \mathrm{mmol})$, DMSO $(2.0 \mathrm{~mL}), \mathrm{MW}$ $\left(100{ }^{\circ} \mathrm{C}\right), 5 \mathrm{~min}$. Yields are for the isolated product. ${ }^{b}$ The reaction was carried out in 1,2-dichloroethane $(2.0 \mathrm{~mL})$ and diphenyl sulfoxide $(3 \mathrm{mmol}), \mathrm{MW}\left(100{ }^{\circ} \mathrm{C}\right), 5 \mathrm{~min}$.

To demonstrate the practicality, a scaled-up synthesis of sulfoxonium ylide $\mathbf{2 b}$ (67\% yield, $1.13 \mathrm{~g}$ scale) was carried out. However, small amounts of byproducts were unavoidable during gram-scale synthesis. This reaction can also be carried out at $\mathrm{rt}$ for $12 \mathrm{~h}$ with almost the same yield.

Next, we investigated the analogues preparation of sulfonium ylides from sulfides. Applying the same conditions as for the formation of sulfoxonium ylides, but replacing the sulfoxide (DMSO) with sulfides 5 (3 mmol) in 1,2-dichloroethane as solvent, provided a variety of sulfonium ylides $\mathbf{6 a}-\mathbf{e}$ from $\beta$ keto esters or 1,3-diketone (1 mmol) (Scheme 4). Pleasingly, the intramolecular coupling of sulfide with active methylene compound yielded sulfonium ylide $\mathbf{6} \mathbf{f}$ in $51 \%$ yield.

Scheme 4. Scope and Limitations of Sulfonium Ylide Formation $^{a}$
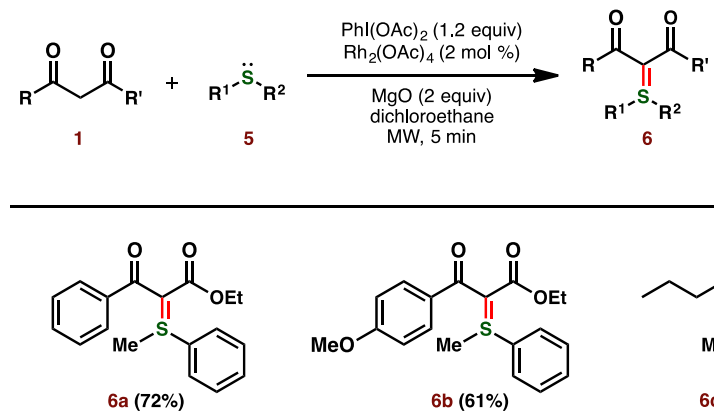<smiles>CCOC(=O)C(C(=O)c1ccc(OC)cc1)=S(C)c1ccccc1</smiles><smiles>CCCC(=O)C(C(=O)OCC)=S(C)c1ccccc1</smiles><smiles>CS(C)=C(C(=O)c1ccccc1)C(=O)c1ccccc1</smiles>

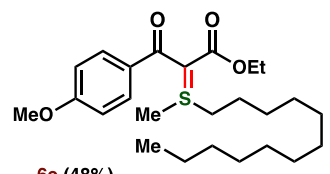

$6 d(52 \%)^{b}$

$6 e(48 \%)$

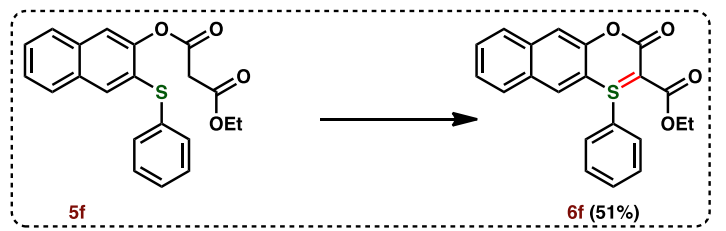

${ }^{a}$ Reaction conditions: 1 ( $\left.1 \mathrm{mmol}\right), 5$ (3 mmol), PhI(OAc) $)_{2}(1.2$ $\mathrm{mmol}), \mathrm{Rh}_{2}(\mathrm{OAc})_{4}(2 \mathrm{~mol} \%), \mathrm{MgO}$ (2 mmol), 1,2-dichloroethane $(2.0 \mathrm{~mL}), \mathrm{MW}\left(100{ }^{\circ} \mathrm{C}\right), 5 \mathrm{~min}$. Yields are for the isolated product. ${ }^{b}$ The reaction was carried out in dimethyl sulfide and 1,2dichloroethane $(1: 1)$ at $\mathrm{rt}$.

A plausible reaction pathway for the formation of sulfur ylides is shown in Scheme 5. First, the active methylene compound reacts with $\mathrm{PhI}(\mathrm{OAc})_{2}$ under basic condition to give an iodonium ylide, which further generates a rhodium carbene complex with $\mathrm{Rh}(\mathrm{OAc})_{2}$. This carbene complex is trapped by sulfide or sulfoxide to generate the corresponding sulfur ylide.

\section{Scheme 5. Plausible Reaction Mechanism}

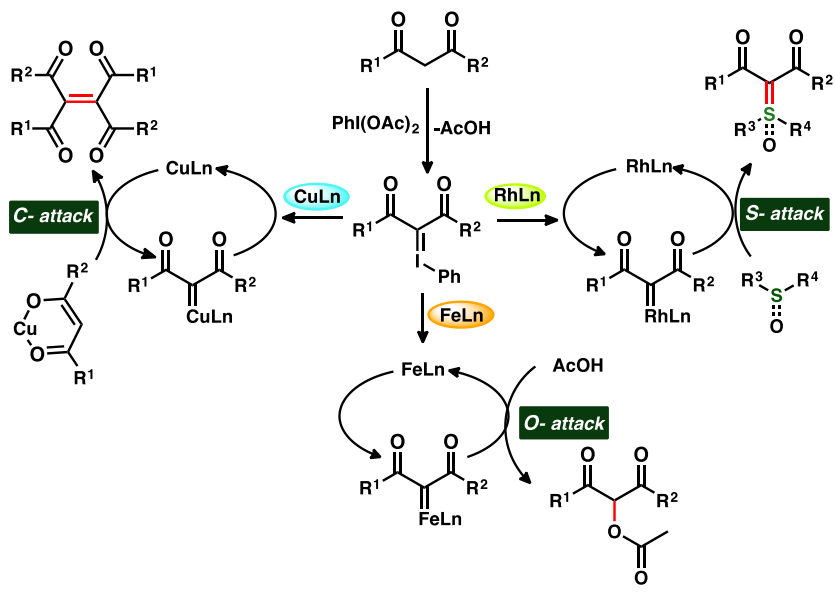

Under copper catalyzed conditions, the copper may increase the nucleophilicity of the active methylene compound and lead to attack on the in situ generated carbenoid to give dimerized product 3 (Scheme 5). ${ }^{14}$ In the presence of iron, a metal carbene can be generated directly ${ }^{15}$, or iron can generate the carbene by functioning as a Lewis acid. ${ }^{16}$ The resulting active 
carbene reacts with acetic acid, which is a byproduct of iodonium ylide. ${ }^{17}$. Although literature supports that different metal carbenoids exhibit significantly different reactivity under similar conditions, ${ }^{18}$ detailed studies are needed to understand the switch in chemoselectivity in the present study.

Acceptor/acceptor sulfonium ylides $\mathbf{6}$ have been explored in transition metal and photoredox catalyzed annulation reactions ${ }^{19}$ forming hetero- and carbocycles and group transfer reactions..$^{20}$ As the reactivity of acceptor/acceptor sulfoxonium ylides $\mathbf{2}$ is unknown, we investigated the possibility of activating sulfoxonium ylides $\mathbf{2}$ as a new acceptor/acceptor carbene for $\mathrm{N}-\mathrm{H}$ and $\mathrm{O}-\mathrm{H}$ insertions. Owing to their high stability and solubility, these sulfur ylides may overcome the limitations of iodonium ylide-derived carbenoids such as low solubility in most solvents, purification requirements, and instability. ${ }^{21}$ Treatment of sulfoxonium ylide 2 (1.0 equiv) with various anilines (1.2 equiv) in the presence of $[\operatorname{Ir}(\mathrm{COD}) \mathrm{Cl}]_{2}(2 \mathrm{~mol} \%)$ in toluene at $150{ }^{\circ} \mathrm{C}$ under microwave reaction conditions afforded N-H insertion products 7 (Scheme 6). ${ }^{8}$ Surprisingly, unlike acceptor/acceptor diazo carbenes, these ylides did not undergo $\mathrm{O}-\mathrm{H}$ insertion with phenols under metal catalyzed conditions. $^{22}$ Instead, one pot reaction of these ylides with aniline and phenol shows excellent chemoselective N-H insertion over $\mathrm{O}-\mathrm{H}$ insertion. ${ }^{23}$

Scheme 6. N-H Insertion of Sulfoxonium Ylides ${ }^{a}$
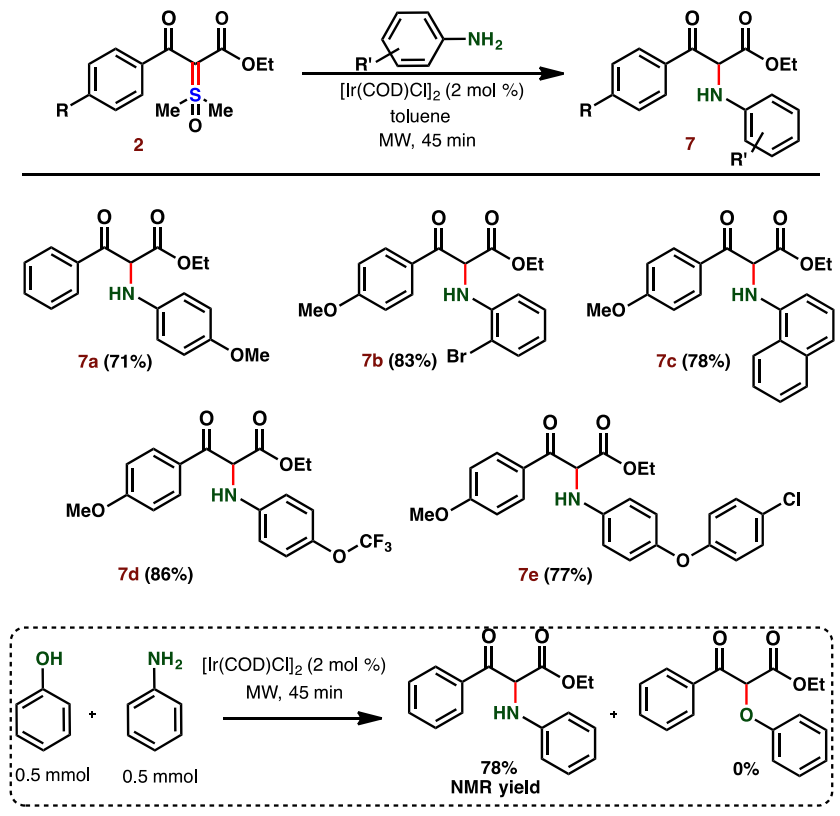

${ }^{a}$ Reaction conditions: 2 (0.5 mmol), anilines $(0.6 \mathrm{mmol})$, $[\operatorname{Ir}(\mathrm{COD}) \mathrm{Cl}]_{2}(2 \mathrm{~mol} \%)$, toluene $(2.0 \mathrm{~mL}), \mathrm{MW}\left(150{ }^{\circ} \mathrm{C}\right), 45$ min. Yields are for the isolated product.

In conclusion, we have developed a general and expedient procedure for the preparation of sulfoxonium and sulfonium ylides. Under rhodium-catalyzed conditions, active methylene compounds, such as $\beta$-diketoesters and $\beta$-diketones, coupled with commercially available inexpensive sulfide and sulfoxides to furnish sulfur ylides in moderate to good yields. Under similar reaction conditions, an unprecedented catalyst-based chemoselectivity switch was observed, favoring different types of nucleophiles. Furthermore, we established that sulfoxonium ylides can be used as novel acceptor/acceptor carbene precursors for chemoselective $\mathrm{N}-\mathrm{H}$ bond insertion of various anilines.

\section{ASSOCIATED CONTENT}

\section{Supporting Information}

Details on experimental procedures, characterization data of all compounds.

The Supporting Information is available free of charge on the ACS Publications website.

\section{AUTHOR INFORMATION}

\section{Corresponding Author \\ * janakiray.vaitla@uit.no}

\section{Author Contributions}

The manuscript was written through contributions of all authors. All authors have given approval to the final version of the manuscript.

\section{ACKNOWLEDGMENT}

This work has received support from the Research Council of Norway (Grant No. 231706) and through the Troms $\varnothing$ Research Foundation (Grant No. TFS2016KHH).

\section{REFERENCES:}

(1) (a) Corey, E. J.; Chaykovsky, M., J. Am. Chem. Soc. 1965, 87, 1353. (b) Johnson, A. W.; Hruby, V. J.; Williams, J. L., J. Am. Chem. Soc. 1964, 86, 918.

(2) (a) Aggarwal, V. K.; Winn, C. L., Acc. Chem. Res 2004, 37, 611. (b) Li, A.-H.; Dai, L.-X.; Aggarwal, V. K., Chem. Rev. 1997, 97, 2341. (c) Liu, Y.; Shao, X.; Zhang, P.; Lu, L.; Shen, Q., Org. Lett. 2015, 17, 2752.

(3) (a) Lu, L. Q.; Chen, J. R.; Xiao, W. J., Acc. Chem. Res 2012, 45, 1278. (b) Lu, L. Q.; Cao, Y. J.; Liu, X. P.; An, J.; Yao, C. J.; Ming, Z. H.; Xiao, W. J., J. Am. Chem. Soc. 2008, 130, 6946. (c) Kramer, S.; Skrydstrup, T., Angew. Chem. Int. Ed. 2012, 51, 4681. (d) Chen, J. R.; Dong, W. R.; Candy, M.; Pan, F. F.; Jorres, M.; Bolm, C., J. Am. Chem. Soc. 2012, 134, 6924.

(4) (a) Nicolaou, K. C.; Sun, Y. P.; Guduru, R.; Banerji, B.; Chen, D. Y., J. Am. Chem. Soc. 2008, 130, 3633. (b) Sarabia, F.; MartinGalvez, F.; Chammaa, S.; Martin-Ortiz, L.; Sanchez-Ruiz, A., J. Org. Chem. 2010, 75, 5526.

(5) Reddy, G. R.; Sarada, S., Biochem. Int. 1989, 19, 215.

(6) (a) Burtoloso, A. C. B.; Dias, R. M. P.; Leonarczyk, I. A., Eur. J. Org. Chem. 2013, 2013, 5005. (b) Xu, Y.; Yang, X.; Zhou, X.; Kong, L.; Li, X., Org. Lett. 2017, 19, 4307. (c) Guo, X.; Han, J.; Liu, Y.; Qin, M.; Zhang, X.; Chen, B., J. Org. Chem. 2017. (d) Barday, M.; Janot, C.; Halcovitch, N. R.; Muir, J.; Aïssa, C., Angew. Chem. 2017, 129, 13297. (e) Xu, Y.; Zhou, X.; Zheng, G.; Li, X., Org. Lett. 2017, 19, 5256.

(7) (a) Bio, M.; Javadi, G.; Song, Z., Synthesis 2004, 2005, 19. (b) Proctor, L. D.; Warr, A. J., Org. Process Res. Dev. 2002, 6, 884.

(8) Vaitla, J.; Bayer, A.; Hopmann, K. H., Angew. Chem. Int. Ed. 2017, 56, 4277.

(9) Aggarwal, V. K.; Thompson, A.; Jones, R. V. H., Tetrahedron Lett. 1994, 35, 8659. 
(10) (a) Ando, W.; Yagihara, T.; Tozune, S.; Migita, T., J. Am. Chem. Soc. 1969, 91, 2786. (b) Ando, W.; Yagihara, T.; Tozune, S.; Imai, I.; Suzuki, J.; Toyama, T.; Nakaido, S.; Migita, T., J. Org. Chem. 1972, 37, 1721. (c) Aggarwal, V. K.; Thompson, A.; Jones, R. V. H.; Standen, M. C. H., J. Org. Chem. 1996, 61, 8368. (11) (a) Huang, X.; Goddard, R.; Maulide, N., Angew. Chem. Int. Ed. 2010, 49, 8979. (b) Huang, X.; Patil, M.; Fares, C.; Thiel, W.; Maulide, N., J. Am. Chem. Soc. 2013, 135, 7312.

(12)Price given by Sigma-Aldrich (CAS Number 32133-82-7)

(13) (a) Mo, S.; Li, X.; Xu, J., J. Org. Chem. 2014, 79, 9186. (b) Muller, P.; Ghanem, A., Org. Lett. 2004, 6, 4347. (c) Murphy, G. K.; West, F. G., Org. Lett. 2006, 8, 4359. (d) Wurz, R. P.; Charette, A. B., Org. Lett. 2003, 5, 2327.

(14) Gololobov, Y. G.; Golding, I. R.; Galkina, M. A.; Lokshin, B. V.; Garbuzova, I. A.; Petrovskii, P. V.; Starikova, Z. A.; Averkiev, B. B., Russ. Chem. Bull. 2006, 55, 883.

(15) Zhu, S. F.; Cai, Y.; Mao, H. X.; Xie, J. H.; Zhou, Q. L., Nat. Chem. 2010, 2, 546.

(16) Cui, J.; Duan, Y.-N.; Yu, J.; Zhang, C., Org. Chem. Front. 2016, 3, 1686.

(17) Hunter, A. C.; Chinthapally, K.; Sharma, I., Eur. J. Org. Chem. 2016, 2016, 2260.

(18) Deng, Y.; Jing, C.; Arman, H.; Doyle, M. P., Organometallics 2016, 35, 3413.

(19) (a) Klimczyk, S.; Misale, A.; Huang, X.; Maulide, N., Angew. Chem. Int. Ed. 2015, 54, 10365. (b) Klimczyk, S.; Huang, X.; Kahlig, H.; Veiros, L. F.; Maulide, N., J. Org. Chem. 2015, 80, 5719. (c) Sabbatani, J.; Huang, X.; Veiros, L. F.; Maulide, N., Chem. Eur. J. 2014, 20, 10636. (d) Huang, X.; Peng, B.; Luparia, M.; Gomes, L. F.; Veiros, L. F.; Maulide, N., Angew. Chem. Int. Ed. 2012, 51, 8886. (e) Xia, X. D.; Lu, L. Q.; Liu, W. Q.; Chen, D. Z.; Zheng, Y. H.; Wu, L. Z.; Xiao, W. J., Chem. Eur. J. 2016, 22,8432 .

(20) (a) Liu, Y.; Lu, L.; Shen, Q., Angew. Chem. Int. Ed. 2017. (b) Huang, X.; Goddard, R.; Maulide, N., Chem. Commun. 2013, 49, 4292. (c) Klose, I.; Misale, A.; Maulide, N., J. Org. Chem. 2016, 81,7201 .

(21) (a) Muller, P., Acc. Chem. Res 2004, 37, 243. (b) Zhu, C.; Yoshimura, A.; Ji, L.; Wei, Y.; Nemykin, V. N.; Zhdankin, V. V., Org. Lett. 2012, 14, 3170.

(22) Honey, M. A.; Blake, A. J.; Campbell, I. B.; Judkins, B. D.; Moody, C. J., Tetrahedron 2009, 65, 8995.

(23) Hansen, S. R.; Spangler, J. E.; Hansen, J. H.; Davies, H. M., Org. Lett. 2012, 14, 4626. 